\title{
Erratum: Storage Properties of Low Fat Fish and Rice Flour Coextrudates
}

\author{
Tumuluru Jaya Shankar • Shahab Sokhansanj • \\ Sukumar Bandyopadhyay • A. S. Bawa
}

Published online: 1 December 2010

(C) Springer Science+Business Media, LLC 2010

Erratum to: Food Bioprocess Technol (2010) 3:481-490 DOI 10.1007/s11947-008-0170-y

The original version of this article unfortunately missed the second affiliation of Shahab Sokhansanj. The missing affiliation is provided below.

The online version of the original article can be found at http://dx.doi. org/10.1007/s11947-008-0170-y.

T. J. Shankar $(\bowtie) \cdot$ S. Sokhansanj

Department of Chemical and Biological Engineering,

University of British Columbia,

2360, East Mall,

Vancouver V6T 1Z3, Canada

e-mail: stumuluru@chml.ubc.ca

S. Sokhansanj

Environmental Sciences Division,

Oak Ridge National Laboratory,

Oak Ridge, Tennessee 37831, USA

S. Bandyopadhyay

Agricultural and Food Engineering Department,

Indian Institute of Technology,

Kharagpur, India

\section{A. S. Bawa}

Defence Food Research laboratory,

Mysore, India 